\title{
Unusual pigments found in a painting by Giotto (c. 1266-1337) reveal diversity of materials used by medieval artists
}

\author{
Barbara H. Berrie ${ }^{1 *}$, Marco Leona ${ }^{2}$ and Richard McLaughlin ${ }^{3}$
}

\begin{abstract}
Background: The important trecento Florentine artist Giotto (c. 1266-1337) is renowned for his naturalistic and realistic works in tempera and fresco. His innovative paintng style involved painting expressive, emotive faces and use of pictorial devices for depicting space. This report focuses on the analysis of the materials and methods used in a panel in the collection of the National Gallery of Art, Madonna and Child (1310/1315).

Results: Giotto used inky washes under thin layers of egg tempera paint. Yellow iron earth and lead tin yellow are present in the paint used to depict the lining of the Virgin's mantle. SEM-EDX of one of the yellow pigments confirmed it is lead tin yellow type II, $\mathrm{PbSn}_{1-x} \mathrm{Si}_{x} \mathrm{O}_{3}$. The ratio of colorant to the glassy phase indicates this material was produced for use as a pigment rather than as a glass. Ultramarine was not used in this painting, azurite is the blue pigment. The azurite used here does not contain elemental impurities, however malachite and the rare green-blue mineral mixite, $\mathrm{BiCu}_{6}(\mathrm{OH})_{6}\left(\mathrm{AsO}_{4}\right)_{3}\left(\mathrm{H}_{2} \mathrm{O}\right)_{3}$, are found in the blue paint.
\end{abstract}

Keywords: Giotto di Bordone, Mixite, Lead tin yellow type II, Raman, EBSD, Copper arsenates

\section{Background}

The important trecento Florentine artist Giotto di Bordone (c. 1265-1337) is renowned for his naturalistic and realistic works in tempera and fresco. His innovative style was revered in his own time and involved painting expressive, emotive faces and employing novel pictorial devices to communicate a sense of space to the viewer. The panel Madonna and Child attributed to Giotto in the collection of the National Gallery of Art, Washington, DC, is dated c. 1310/1315 (Fig. 1). It evokes the tenderness of the human bond between the Christ Child and his Mother. The panel is believed to have been part of a polyptych, but its original location is unknown.

During a recent conservation treatment a technical examination was undertaken to obtain information on the materials and methods used in creating this panel to establish the connection between it and other paintings

\footnotetext{
*Correspondence: b-berrie@nga.gov

${ }^{1}$ Scientific Research Department, National Gallery of Art, Washington, DC, USA

Full list of author information is available at the end of the article
}

which might have been part of the same altarpiece [1]. Giotto used techniques similar to those described for painting on wood in 1400 by the Florentine artist Cennino Cennini which have been observed in works by his contempories [2]. The artist used an inky wash to lay in the shaded parts of the flesh and the mantle. Then, working in egg tempera he applied overlapping strokes of thin paint to model the forms. For the most part the pigments he used are part of the typical early fourteenth century palette, minus the expensive blue pigment lapis lazuli which is often found in early fourteenth century panels and frescos. However, microanalysis has shown in addition to typical colorants the unexpected presence of a green-blue mineral, mixite, a copper-bismuth arsenate, which has not been reported in any paintings before now.

In this paper, we focus on the use of microscopy and microanalysis to obtain a more complete characterization of the yellow pigment, a variant of glassy lead tin yellow type II, the quality of the azurite, and the discovery of the presence of the green-blue copper mineral, mixite. The novel finding of mixite is a reminder that painters and other artists and craftsmen used a diverse range of

\section{Springer}




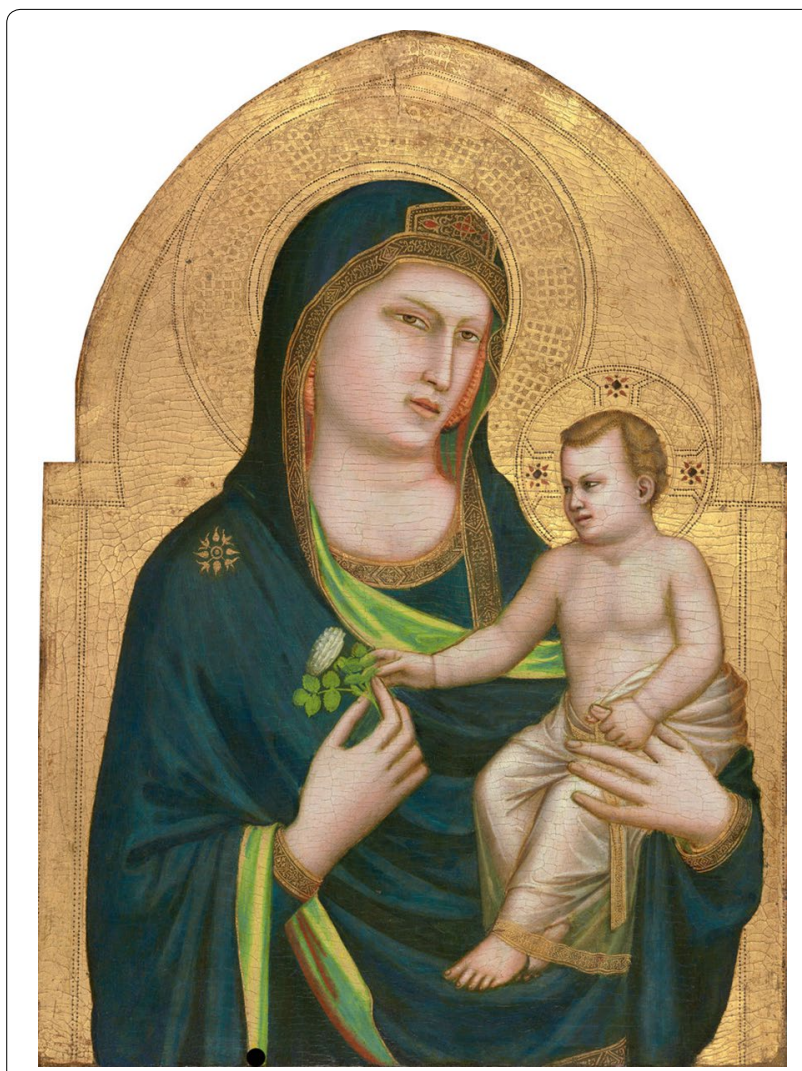

Fig. 1 Giotto, Madonna and Child c. 1310/1315, Samuel H. Kress Collection, National Gallery of Art, Washington, D.C. (1939.1.256). The location of the samples described here is indicated by a black dot

materials, and instrumental analysis is valuable for their identification, complementing and augmenting information given in treatises. The results may also help the investigation of geographical sources, and hence trade, of pigments used by trecento artists.

\section{Results}

This work relied on close visual stereomicroscopy of the surface of the painting and air-path $\mathrm{x}$-ray fluorescence analysis (XRF) analysis. A small number of cross section samples and paint scrapings were obtained for more detailed characterization of the pigments. All the samples described here were taken from the bottom edge of the panel at or close to the site in the Madonna's robe indicated by a black dot in Fig. 1. The samples were analyzed using scanning electron microscopy with energy dispersive x-ray analysis (SEM-EDX), polarized light microscopy (PLM), microRaman spectroscopy and electron backscatter diffraction (EBSD). EBSD was crucial to identificaton of the phases. Electrons can be diffracted by atoms vibrating in lattice planes of crystalline compounds. These diffracted electrons form cones which due to the low angle of scattering appear as lines on a detector. The lines from different planes of atoms form Kikuchi patterns which can be related to crystal structures without need for a specific orientation of the crystals. The Kikuchi patterns can be compared to patterns from standard and vouchered samples. Pattern formation is a result of electron diffraction at the sample surface down to $20-30 \mathrm{~nm}$. For pattern acquisition, a sample is tilted at high angle, typically at $70^{\circ}$, reducing spatial resolution of the analysis, however excellent patterns can be obtained from crystallites as small as $10 \mathrm{~nm}$, therefore EBSD can be very useful for identification of pigment particles.

The cross-section samples were extraordinarily sensitive to water used during the initial grinding and polishing process of preparing the cross sections-much more than typical, perhaps due to the ground having a low concentration of gypsum in glue. This sensitivity meant that the surface could not be polished flat. Argon ion milling was used to try to smooth the surface, but this was not successful. The difficulty of the sample work up meant that the analyses had to be conducted on rough surfaces, nevertheless we were able to obtain interesting results and novel discoveries.

From surface examination of the painting the lining of the Virgin's mantle looks as if it had been painted using a glaze of azurite over a layer of yellow paint. However, cross sections show that in the painting there are passages where the yellow is on top of the blue and others where the colors are mixed (Fig. 2).

XRF confirmed the general palette of inorganic pigments by inference from elemental compositon as lead white, yellow iron earths, green earth, azurite, lead tin yellow, and vermilion. Spectra from the blue drapery contained peaks for lead, mercury, and a very small peak for the $K \beta$ line of arsenic. This was tentatively thought to be due to orpiment, a pigment that has been found in Giotto's works, but a close surface examination did not reveal any of the typical yellow tablet-shaped particles of orpiment.

\section{Lead tin yellow type II}

Two yellow pigments were found: iron earth and lead tin yellow type II, as expected for a fourteenth century painting. Lead-tin yellow type II is a term used to cover a range of pigments that are opaque yellow glasses or glassy materials [3]. The formula is given as $\mathrm{PbSn}_{1-\mathrm{x}} \mathrm{Si}_{\mathrm{x}} \mathrm{O}_{3}$ where $x \geq 0$. The crystallographic group of the endmember $\mathrm{PbSnO}_{3}$ is cubic. The backcatter electon (BSE) image of a single particle at higher magnification is shown in Fig. 3a. This image and EDX spectra obtained at diffierent spots within the pigment particle (Fig. 3b) show that the partcle is composed of a $\mathrm{Ca}-\mathrm{Pb}-\mathrm{Si}$ matrix holding densely packed crystallites of lead tin oxide, lead silicate and lead 


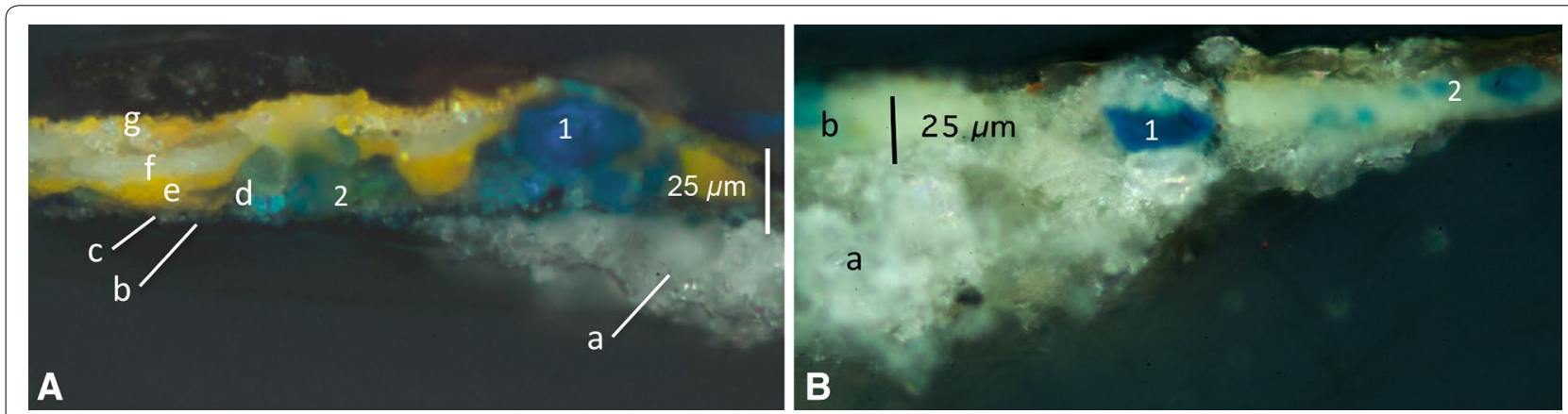

Fig. 2 Cross sections from the yellow-green lining of the Virgin's mantle at the bottom edge of the panel. Two samples (A and B) both from the very bottom edge of the panel at the black dot in Fig. 1. A was modified by stack focussing using a plug-in for Image J. The scale bars are $25 \mu \mathrm{m}$. The layers in $\mathbf{A}$ are from the bottom: a gesso ground; $b$ a dark inky wash; $c$ a white wash that is more easily visualized in Fig. $5 a ; d$ an uneven layer of blue and green particles, azurite (labeled 1), malachite, mixite (labeled 2); e yellow iron oxide; $f$ lead white; $g$ lead tin yellow. The sample in B, taken adjacent to that in $\mathbf{A}$, is simpler: $a$ a layer of gesso is covered by $b$ paint with a mixtures of lead tin yellow and copper-based green and blue pigments, azurite (1) and mixite (2)

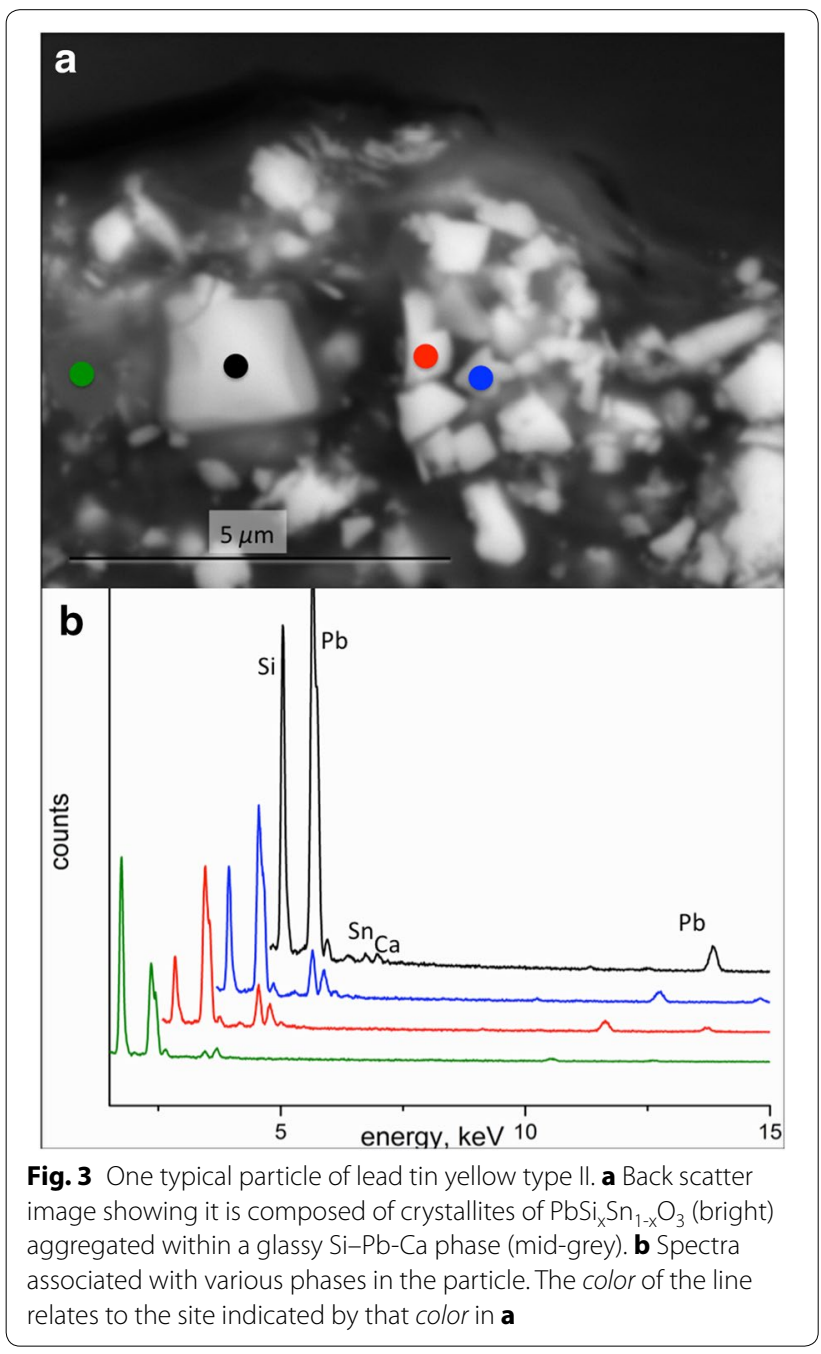

tin silicate-the grey levels giving a clue to the diversity of the composition of the particles. The Kikuchi pattern from EBSD of one particle of the predominant light grey level matches the pattern of $\mathrm{PbSnO}_{3}$ [4]. A slightly darker phase contains silicon, calcium and lead, but no tin. None of the phases contain iron, zinc or potassium-elements that have been found in the pigment used by later artists. This indicates that a simple recipe was used for the production of this colorant.

\section{Azurite}

The blue paint used for the Virgin's mantle is not the deep blue of lapis lazuli or ultramarine, rather it is colored predominantly by azurite. Transmitted light microscopy of a small scraping of the paint from under the brown trim on the mantle shows that the particle size range of the pigment used in this painting is wide: while most particles are small, some are $35 \mu \mathrm{m}$ long, giving the paint a saturated, intense color. Only a small proportion of white pigments was added to the blue paint. The EBSD pattern confirmed the identity of the blue mineral (Fig. 4a, b). The EDX spectrum (Fig. 4c) of the particle labelled 1 in Fig. 2a shows that the azurite used in this work is very pure, and does not contain any detectable transition element impurities or substitutions, such as zinc or manganese, which are sometimes found in azurite or malachite $[5,6]$. The cross sections do not contain red particles which are often observed in azurite paint, which have been shown to be naturally occuring iron oxide impurities [7].

In addition to azurite, there are some smaller green and green-blue particles in the paint. Some of these contain only copper, determined using SEM-EDX, and have a 

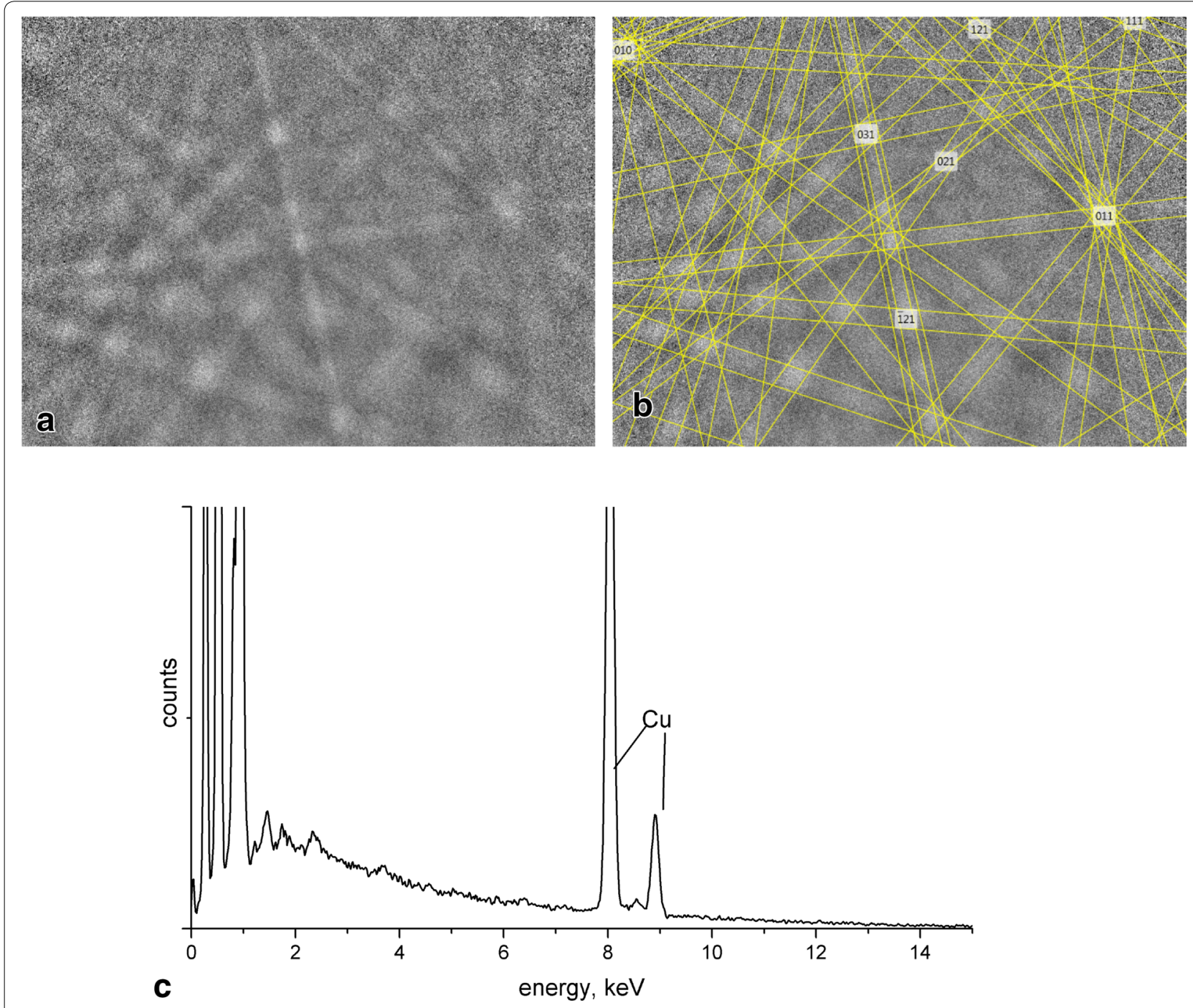

Fig. 4 Analysis of the azurite. a the Kikuchi pattern of the particle marked 1 in Fig. 2. b The pattern with the solution for azurite overlaid (ICSD [16770]). c The EDX spectrum of the particle

grey level in the BSE image (Fig. 5a) very similar to that of the azurite. These are likely malachite, which is often geologically associated with azurite and no further analysis was undertaken. Other particles, as already noted, have a more complex compostition and are discussed next.

\section{Mixite}

The most interesting finding was the identification of a $\mathrm{Cu}-\mathrm{Bi}$ arsenate mineral mixed into the paint. Several smaller green-blue particles in the cross sections and in dispersed samples from the blue drapery are brighter than azurite in the BSE image which implies they have a higher average atomic number. Two green-blue particles in the center of the section in Fig. 2A have a crystal habit that is approximately columnar hexagonal. These particles can be seen to extend lengthwise into the the sample. They are small with a diameter of c. $8 \mu \mathrm{m}$ and an observable length of c. $20 \mu \mathrm{m}$. Their appearance in BSE is very similar to that published of one sample of the mineral mixite which has bundles of acicular crystals [8]. A map of the distribution of the elements copper, bismith, arsenic and calcium is shown in Fig. 5b. Bismuth and arsenic are located in these particles and qualitative elemental analysis indicates they are ternary metal oxides of copper, arsenic and bismuth. A representative spectrum of the particles labeled 2 in Fig. 2 is presented in Fig. 5c. The green-blue particles contain varying proportions of bismuth, higher in some and not detectable in others; 


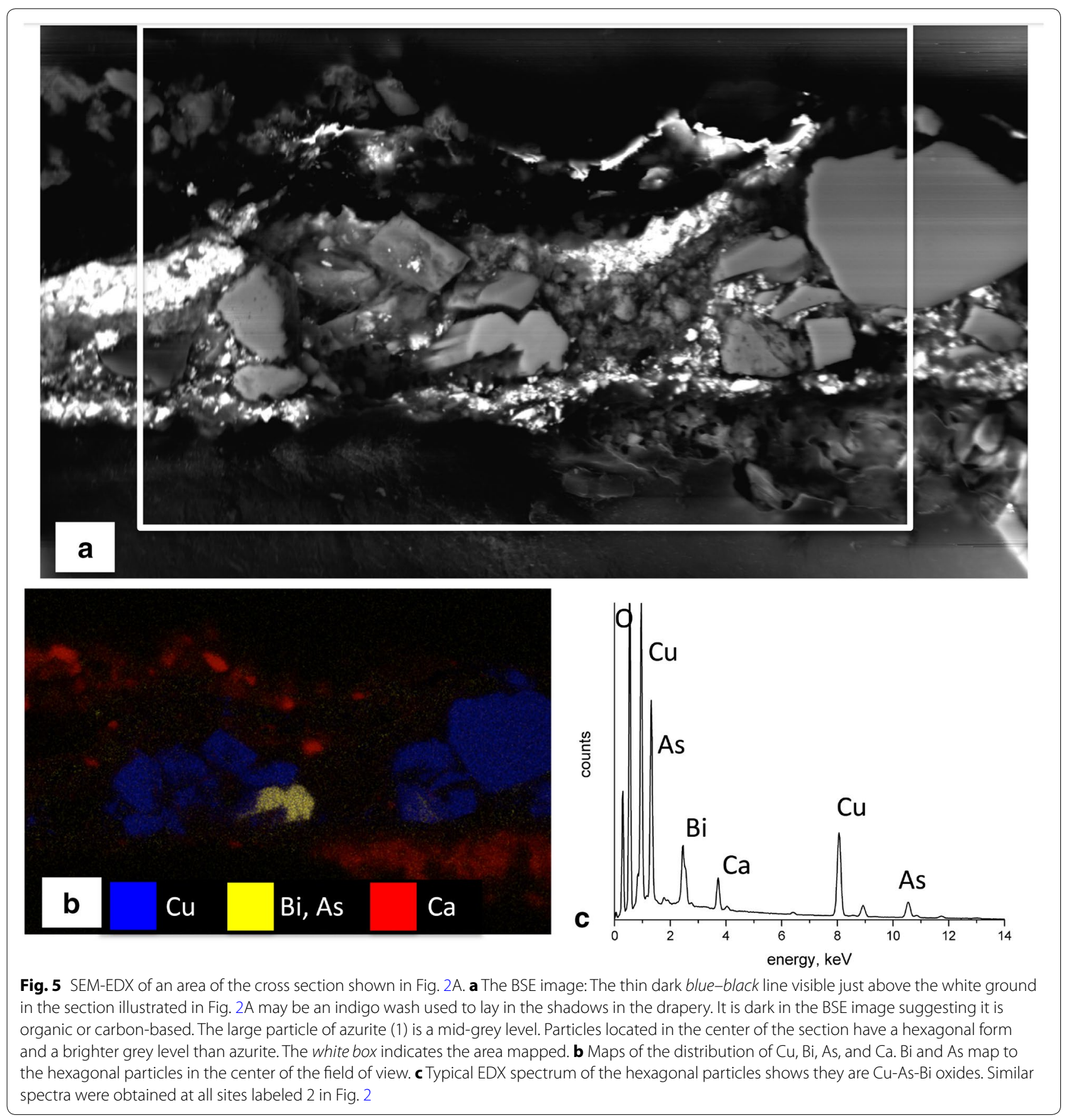

however, the sample was too rough for reliable quantification of the phases [9] therefore, microRaman and EBSD were employed for further characterization.

The microRaman spectrum obtained from one of the green-blue particles at the top right edge of the sample illustrated in Fig. 2B is shown in Fig. 6. The sloping background is due to fluorescence from the mineral, a common problem for green/blue compounds which can affect the ability to measure Raman emission. For this sample, peaks occur at $853,825,472,457(\mathrm{sh})$, and $420 \mathrm{~cm}^{-1}$. These can be assigned to the symmetric $\left(v_{s}\right)$ and asymmetric $\left(v_{a s}\right)$ stretches and bending modes of the orthoarsenate group $\left(\mathrm{AsO}_{4}{ }^{3-}\right)$ and hydroxyorthoarsenates ( $\mathrm{HAsO}_{4}{ }^{2-}$ and $\mathrm{H}_{2} \mathrm{AsO}_{4}{ }^{-}$) in a distorted tetrahedral symmetry, while the absence of bands at $867-870 \mathrm{~cm}^{-1}$ may indicate the absence of $\mathrm{H}_{2} \mathrm{AsO}_{4}{ }^{-}$moeity $[10,11]$. These Raman shifts are similar to those measured by Frost et al. for two samples of mixite-one of which from the Boss 


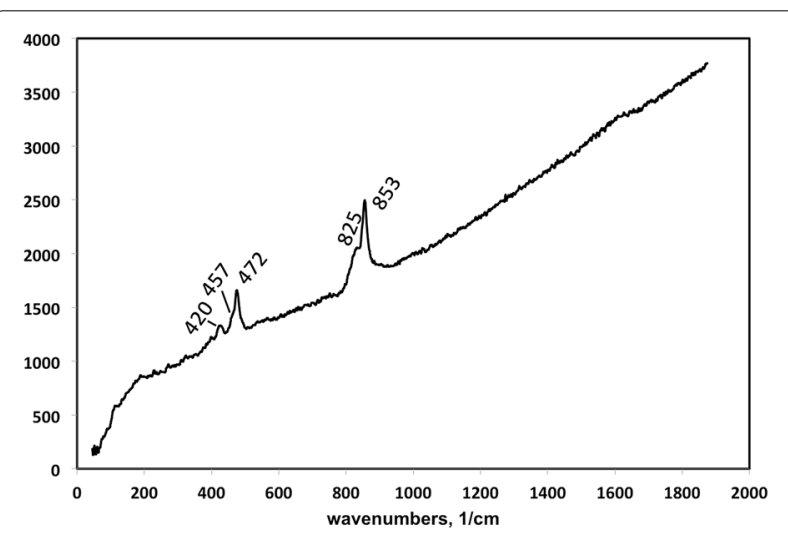

Fig. 6 Raman spectrum of a green-blue particle at the right hand edge of the cross section shown in Fig. 2B

Tweed mine in Montana has $\mathrm{v}_{2} 851.8$ and $830.8 \mathrm{~cm}^{-1}$ and $\mathrm{v}_{4}$ (bending mode) 475.4 and $473.7 \mathrm{~cm}^{-1}$, values that are comparable to the mineral in Giotto's paint [8].

Since the Raman spectrum obtained from the greenblue pigment in the cross section could be due to a number of arsenate-containing minerals [12], we obtained an EBSD pattern to confirm the identification. The rough surface of the cross sections (Fig. 7) was the first challenge to acquiring good diffraction patterns; additionally some damage to the cross section due to heating by laser radiation during Raman spectroscopy had occurred on the top surface of the particles. However, a diffraction pattern was obtained from the rounded side of one of the particles (Fig. 8). The pattern matches the phase $\mathrm{BiC}$ $\mathrm{u}_{6}(\mathrm{OH})_{6}\left(\mathrm{AsO}_{4}\right)_{3}\left(\mathrm{H}_{2} \mathrm{O}\right)_{3}$ which has hexagonal-low $(6 / \mathrm{m})$

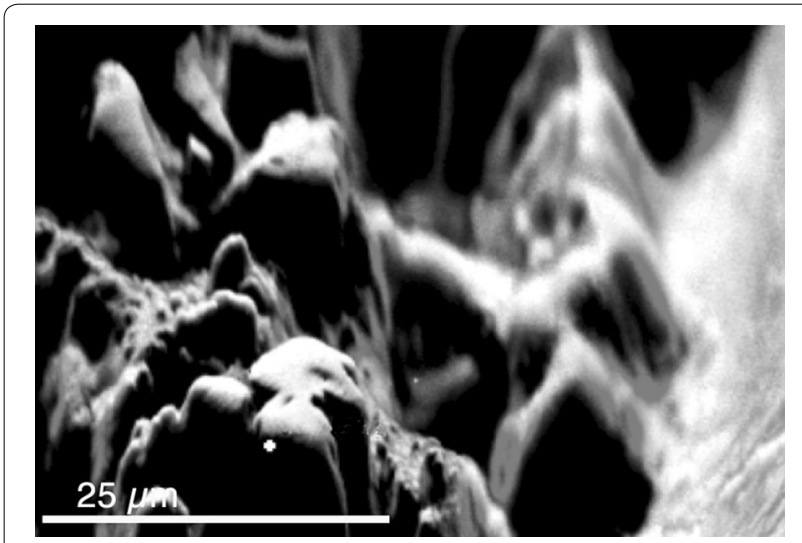

Fig. 7 Forward facing image of the right hand edge of the cross section shown in Fig. 2B. The extreme roughness of the sample is evident. The Bioplastic mounting material is along the right hand side. The white cross indicates the position from which the pattern in Fig. 8 was obtained. It is one of the green-blue particles in the right hand side of the section symmetry, consistent with the apparent crystal habit of the particles observable in the cross sections (see Fig. 5a) [13]. The mixite solution overlaid in Fig. 8b corresponds extremely well to the collected pattern. Furthermore, since no other $\mathrm{Bi}-\mathrm{Cu}-\mathrm{As}-\mathrm{O}$ crystal structures in the ICSD database matches the experimental pattern, we are confident in the identification of the particles in Giotto's paint as the mineral mixite.

\section{Discussion}

There is very little knowledge about where trecento artists such as Giotto obtained their colors, either from the point of view of international trade in color or where individual artists obtained their pigments locally. The results presented here could help provide information on this. The writer/painter Cennini alluded to artists' making some pigments themselves, but purchasing others that were troublesome to synthesize at an apothecary, and he noted that azurite, associated with silver, came from Germany or Siena [14].

The early wide usage of lead-tin yellow appears to have occurred in fourteenth century Tuscan painting, including works by Giotto and his contemporaries. The pigment used in Madonna and Child and other Florentine artists' works likely came from the ceramicists or glass-makers who would have used something similar for a colorant in their own work [15]. There is in fact some evidence for overlap between the Florentine glass-makers' and painters' commissions and materials, even in the early 14th century [16]. Lead tin yellow type II with a similar low proportion of glass as the pigment used in this panel was used to make beads which might have come from Italy that were found in a 13-14th century grave in Lithuania [17]. These are opaque and more similar to enamels than glass in the proportion of the coloring oxides. An early example of the pigment lead tin yellow, a material containing a low amount of $\mathrm{Si}$ was found in a Merovingian (8th C) crucible [18]. The aggregated appearance of the crystallites and no signs of conchoidal fracture at the edges of the clusters suggest the yellow colorant in Giotto's paint was manufactured for use as a pigment and is not pulverized glass, which some later artists used [19]. The inhomogeneity of the particle at high magnification is worth noting. It occurs at a finer scale than the microRaman based on optical microscopy can readily measure.

It is of interest that we have no evidence for Giotto's using ultramarine in this work. It was the most costly and highly prized blue pigment and despite the prestige associated with using ultramarine, azurite was Giotto's choice for this panel. Azurite was widely used during his time. The names ongaro, azzurro tedescho, and azzurro de alemagna were among the terms used for it, adding credence to the notion that in the fourteenth century 

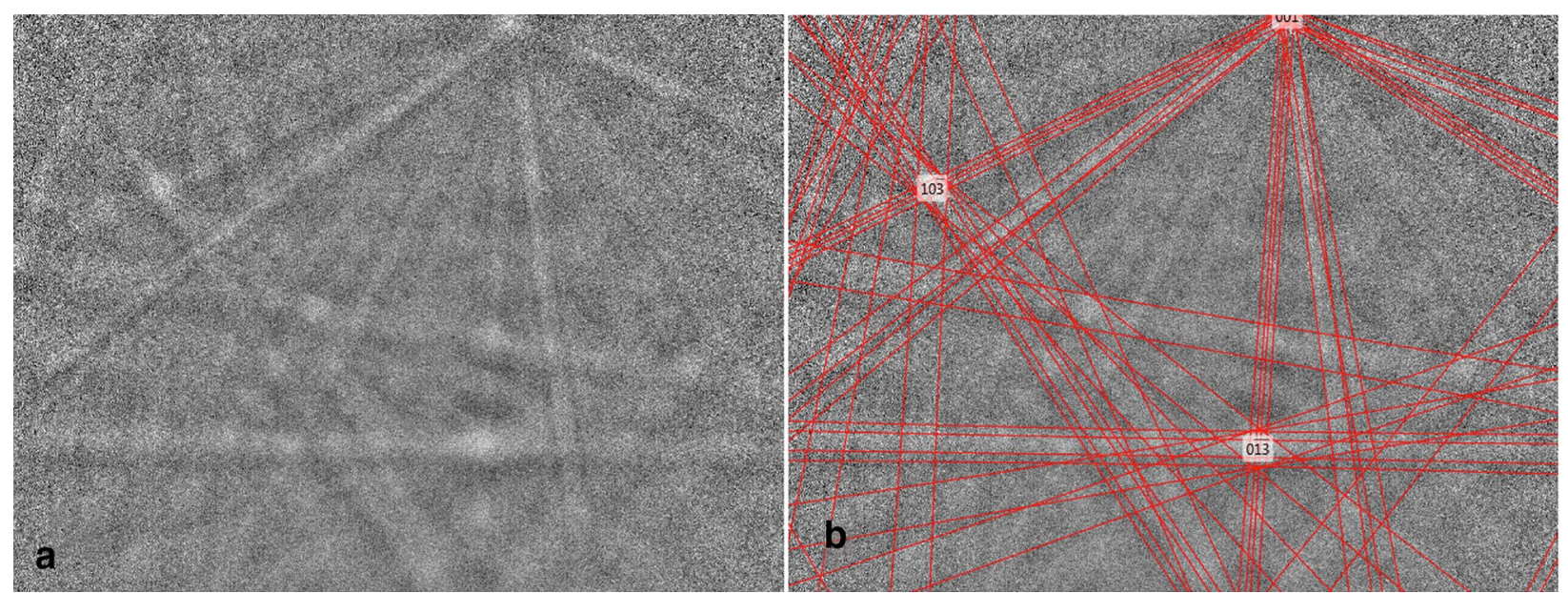

Fig. 8 EBSD pattern obtained from a green-blue particle in the paint. a The Kickuchi pattern obtained at the position marked with a white cross in Fig. 7. b The solution for mixite, $\mathrm{BiCu}_{6}(\mathrm{OH})_{6}\left(\mathrm{AsO}_{4}\right)_{3}\left(\mathrm{H}_{2} \mathrm{O}\right)_{3}$ ( $(\mathrm{CSD}[50061])$, overlaid on the pattern

the source for azurite in Florence was Hungary or Germany. Aru et al. analyzed some minerals from places that may have been the sources for azurite have been analyzed but there is not enough information to be able to locate the source for this pigment [7] since its purity does not provide any evidence for the source of Giotto's supply.

Mixite is a rare secondary mineral that forms in the oxidized zones of copper deposits when bismuth is present. It is often found in supergene enrichment zones, occurring as fibrous needles, associated with azurite and with malachite, a mineral that was an essential green pigment on the painter's palette [20]. Mixite has been identified in places that are understood to have been historical sources for azurite: a number of sites in the Harz Mountains in the Black Forest and the Ore Mountains in Saxony, and in Hungary and the Czech Republic [21]. Although its photostability has not been determined, the mineral is quite thermally stable. In very dry environments it loses water that is considered to be quasi zeolitic, but rehydration occurs readily. Loss of hydroxyl groups that are part of the structural framework does not occur until $523 \mathrm{~K}$ [13]. Therefore, it is unlikely that the mixite in the painting is an alteration product, nor is it prone to degradation in normal circumstances and we can infer that the mixite has been in the paint since Giotto prepared it on his palette.

Few other instances of copper-arsenate minerals in paintings are known. The most relevant occurrence of copper-arsenate minerals in art to the discovery presented here is in wall paintings in Assisi that are attributed to Giotto [22]. X-ray fluorescence analysis of the azurite blues shows the presence of arsenic, antimony, and barium. Olivenite, a green copper arsenate, has been found in wall paintings (mainly 19th century works) in the Ala di Sturo valley in Piedmont [23] near where it occurs in deposits. The green pigment in paintings by the 16th C Italian artist Stefano Sparano in the Musée de Picardie in Amiens is a copper-based colorant with arsenic and zinc impurities, that appears from $x$-ray powder diffraction to be a form of malachite. In much less related works, a calcium-copper arsenate, tirolite, was identified in ancient Persian wall paintings [24], and a copper arsenate mineral was found associated with malachite in a wall painting at Pompei [25]. These limited and isolated occurrences do not shed light on the prevalence of use in early modern times of copper arsenates, which tend to be more green than blue, but they might have been used much more than we have realised since they can easily be overlooked using most analytical methods, particularly non-invasive methods for pigment analysis. The particles are very small, the color between that of malchite and azurite, and the amounts of bismuth and arsenic are low. Bismuth was not detected using air-path XRF.

The presence of the nineteenth century pigments emerald green, $\mathrm{Cu}\left(\mathrm{CH}_{3} \mathrm{COO}\right)_{2} \cdot 3 \mathrm{Cu}\left(\mathrm{AsO}_{2}\right)_{2}$ and Scheele's green - a term applied to copper arsenite of varying compositions-could be inferred from the XRF results, but the Raman spectra of these arsenite compounds are different from those of the mineral in Giotto's paint. Emerald green has medium to strong absorbances at 539, 950, and $1440 \mathrm{~cm}^{-1}$ and only a weak absorbance at $835 \mathrm{~cm}^{-1}$ [26, 27]. Scheele's green has medium to strong Raman absorbances at 370,495 , and $780 \mathrm{~cm}^{-1}$ [27]. 


\section{Conclusions}

The colors Giotto used in Madonna and Child tend to the cooler end of the spectrum. The yellow is a vivid but light color and the blues are the cool tones of azurite compared to the warmer hue of ultramarine often used by Giotto and others in many contemporary works. The lead tin yellow found here is an inhomogeneous material, similar to the pigment used to color glass or enamel. In this painting the green undertone of azurite is intensified by the presence of malachite and the green-blue mineral mixite in the paint. Air-path XRF analysis was insufficient to characterize the nature of the pigment. Although it is more probable that mixite is an adventitious addition rather than a deliberate one, it seems to be present in large enough proportion to have an effect the chromaticity of the paint used, and whether Giotto was aware of its presence or not, the cool blue color was the artist's conscious choice. This confronts our assumptions that artists always preferred the color of ultramarine.

The identification of the rare mineral mixite provides important information regarding the possible sources of the azurite he employed however, discovering the possible sources for mixite will depend on researching the geology and history of mining in Europe. The results of this work remind us that chemical analysis can add to our knowledge base of painting practice and materials, which helps to place artists' works in a broader historical context, including comparison to the materials and methods used by their contemporaries and economic history. These findings add to our understanding of artistic innovation and a better appreciation of the nuance and worth of color in painters' practice.

\section{Methods}

\section{Sampling and optical microscopy}

Minute samples of the painting were obtained by scraping the surface using a surgeon's scalpel. The particulate matter was mounted in Cargille Meltmount $\left(\mathrm{n}_{\mathrm{D}}=1.662\right)$ on glass microscope slides. Paint cross sections were obtained by prising out small samples adjacent to old losses using a pointed surgeon's scalpel. The samples were mounted in a polyester/methacrylate plastic (Bioplastic, Ward Scientific) and cut at right angles to the paint structure, then polished wet on SiC PSA papers (Buehler) or dry MicroMesh cloths. The particulate samples were examined in transmitted polarized light and the cross sections in bright field, dark field, and fluorescence on a Leica DMRX microscope. For transmitted PLM, PL fluotar objectives 20x/0.50 and 50x/0.05-0.55 were used, while for reflected light microscopy PL fluotar D 20x/0.48 and 50x/0.85 objectives were used. For fluorescence microscopy, filter cubes D (excitation filter band pass 355-425 nm (uv and violet), dichroic filter $455 \mathrm{~nm}$, and long pass filter $470 \mathrm{~nm}$ ) and I3 (excitation bandpass filter 450-490 nm (blue), dichroic filter $510 \mathrm{~nm}$, and long pass filter $515 \mathrm{~nm}$ ) were employed. Images were captured using a Canon EOS 1D camera in cr and jpg formats. Stack focusing was performed using ImageJ and a stack focusing plug-in.

\section{Scanning electron microscopy/energy dispersive $x$-ray analysis (SEM-EDX)}

The samples were examined using scanning electron microscopy with energy dispersive $\mathrm{x}$-ray spectroscopy (SEM-EDX) using a Hitachi S3400-N microscope equipped with an Oxford Aztec spectrometer and an Oxford X-Max SDD detector $\left(80 \mathrm{~mm}^{2}\right)$. Cross sections as described above were placed onto a double sided carbon sticky tab adhered to an $\mathrm{Al}$ stub. Particles were spread on a double-sided carbon sticky tab that was adhered to a carbon stub (Ted Pella, Inc.). Samples were examined uncoated using $20 \mathrm{kV}$ at $20-30 \mathrm{~Pa}$.

\section{Election backscatter diffraction (EBSD)}

To obtain EBSD patterns, carbon-coated samples were examined using an Aztec HKL system with a Nordlys Max2 detector on an FEI Quanta 250 FEG SEM. Accelerating voltage was $30 \mathrm{kV}$ and the tilt $70^{\circ}$.

\section{MicroRaman spectroscopy}

Raman spectroscopy was performed using a Bruker Senterra Raman Microscope with a $488 \mathrm{~nm}$ laser and a 1200 line pairs $/ \mathrm{mm}$ grating. The laser beam, at a nominal power of $4 \mathrm{~mW}$ at the laser head was focused onto the sample using an Olympus LMPlanFL $50 \times$ objective. Three $30 \mathrm{~s}$ acquisitions were averaged. No baseline correction was performed.

\section{X-ray fluorescence analysis (XRF)}

XRF spectra were collected using an air-path ArtTax (Röntec, now Bruker) $\mu$-x-ray spectrometer with a $R h$ tube and $60 \mu \mathrm{m}$ polycapillary optics operated at $50 \mathrm{kV}$ and $200 \mu \mathrm{A}$. Analysis live-time was $200 \mathrm{~s}$.

\section{Authors' contributions}

$\mathrm{BHB}$ initiated the investigation, worked up the samples and performed the optical microscopy and intital SEM-EDX work. ML obtained and interpreted the microRaman spectra. RM obtained and interpreted the EBSD data. BHB wrote the paper with input from ML and RM. All authors read and approved the final manuscript.

\section{Author details}

${ }^{1}$ Scientific Research Department, National Gallery of Art, Washington, DC, USA. ${ }^{2}$ Metropolitan Museum of Art, New York, NY, USA. ${ }^{3}$ Oxford Instruments, Concord, MA, USA.

\section{Acknowledgements}

We thank Federico Caro who used ion milling to prepare the samples. Ruth Murray provided support at Oxford Instruments. We are grateful to Claudio Seccaroni for information regarding occurrrences of copper arsenate minerals in paintings and to Lisha Glinsman who performed air-path XRF. 


\section{Competing interests}

The authors declare that they have no competing interests.

Received: 6 October 2015 Accepted: 6 January 2016

Published online: 27 January 2016

\section{References}

1. Dunn JR, Berrie BH, Delaney JK, Glinsman LD. The Creation of Giotto's Madonna and Child: New Insights. In: Barbour D, Gifford EM, editors. Facture, vol. 2. Washington: National Gallery of Art; 2015. p. 2-17.

2. Bomford D, Dunkerton J, Gordon D, Roy A. Italian painting before 1400 London: National Gallery; 1990.

3. Kühn H. Lead-Tin Yellow. In: Roy A, editor. Artists' Pigments: A Handbook of their History and Characteristics, vol. 2. Washington: National Gallery of Art; 1993. p. 83-112.

4. Morgenstern Badarau I, Michel MA. Sur un compose de type pyrochlore de formule $\mathrm{Pb}-2-\mathrm{Sn}-2-\mathrm{O}-6-(\mathrm{H}-2-\mathrm{O}) \mathrm{X}$. Ann Chim (Paris). 1971, 1971:109-24.

5. Martin E, Eveno M: Contribution to the study of old green copper pigments in easel paintings. In 3rd International conference on nondestruc tive testing, microanalytical methods and environment evaluation for study and conservation of works of art. Italian society for nondestructive testing, Brescia 1992, 779-92.

6. Dunkerton J, Roy A. The materials of a group of late fifteenth-century Florentine panel paintings. Natl Gallery Tech Bull. 1996;17:20-31.

7. Aru M, Burgio L, Rumsey MS. Mineral impurities in azurite pigments: artistic or natural selection? J Raman Spec. 2014;45:1013-8. doi:10.1002/ jrs.4469.

8. Frost RL, Weier M, Martens WN, Duong L. Identification of mixite minerals - an SEM and Raman spectroscopic analysis. Min Mag. 2005:69(2):169-77.

9. Newbury DE, Ritchie NWM. Performing elemental microanalysis with high accuracy and high precision by scanning electron microscopy/silicon drift detector energy-dispersive x-ray spectrometry (SEM/SDD-EDS). J Mater Sci. 2015:50(2):493-518. doi:10.1007/s10853-014-8685-2.

10. Frost RL, Weier M, Martens W. Using Raman spectroscopy to identify mixite minerals. Spectrochimica Acta Part A. 2006;63(1):60-5. doi:10.1016/j. saa.2005.04.037

11. Frost RL, Čejka J, Sejkora J, Plášil J, Bahfenne S, Palmer SJ. Raman microscopy of the mixite mineral $\mathrm{BiCu} 6(\mathrm{AsO}) 3(\mathrm{OH}) 6 \cdot 3 \mathrm{H} 2 \mathrm{O}$ from the Czech Republic. J Raman Spectr. 2010;41(5):566-70. doi:10.1002/jrs.2454.

12. Frost RL, Martens WN, Williams PA. Raman spectroscopy of the phaserelated basic copper arsenate minerals olivenite, cornwallite, cornubite and clinoclase. J Raman Spect. 2002;33(6):475-84. doi:10.1002/jrs.880.
13. Miletich $\mathrm{R}$, Zemann J, Nowak M. Reversible hydration in synthetic mixite, $\mathrm{BiCu}_{6}(\mathrm{OH})_{6}\left(\mathrm{AsO}_{4}\right)_{3} \cdot \mathrm{nH}_{2} \mathrm{O}(\mathrm{n} \leq 3)$ : hydration kinetics and crystal chemistry. Phys Chem Miner. 1997;24(6):411-22. doi:10.1007/s002690050055.

14. Cennini C. II Libro dell'Arte. New York: Dover; 1954.

15. Seccaroni C. Giallorino: storia dei pigmenti gialli di natura sintetica. Rome: De Luca Editori D'Arte; 2006.

16. Thompson NM. The Franciscans and the True Cross: the decoration of the Cappella Maggiore of Santa Croce in Florence. Gesta. 2004;43(1):61-79. doi:10.2307/25067092.

17. Bagdzevičienè J, Niaura G, Garškaitè E, Senvaitienė J, Lukšènienė J. Spectroscopic analysis of lead tin yellow pigment in medieval necklace beads from Kernave-Kriveikiskes Cemetery in Lithuania. Chemija. 2011:22(4):216-22.

18. Heck M, Rehren T, Hoffmann P. The production of lead-tin yellow at Merovingian Schleitheim (Switzerland). Archaeometry. 2003;45(1):33-44. doi:10.1111/1475-4754.00095.

19. Roy A, Berrie BH. A new lead-based yellow in the seventeenth century. In: Roy A, Smith P, editors. Painting techniques: history, materials and studio practice. Contributions to the Dublin Congress 7-11 September 1998. London: Dublin: IC; 1998. p. 160-5.

20. Göb S, Wenzel T, Bau M, Jacob DE, Loges A, Markl G. The redistribution of rare-earth elements in secondary minerals of hydrothermal veins, Schwarzwald, southwestern Germany. Canadian Mineralogist. 2011:49(5):1305-33.

21. http://www.mindat.org/min-2730.html. Accessed Aug 28, 2016.

22. Basile G, Fernetti F, Santopadre P, Seccaroni C, Editors: Giotto com'era. Rome: ENEA and De Luca Editore 2007, 26.

23. Aceto M, Gatti G, Agostino A, Fenoglio G, Giordano V, Varetto M, et al. The mural paintings of Ala di Stura (Piedmont, Italy): a hidden treasure investigated. J Raman Spectr. 2012;43(11):1754-60. doi:10.1002/jrs.4066.

24. Stodulski L, Farrell E, Newman R. Identification of ancient Persian pigments from Persepolis and Pasargadae. Stud Conserv. 1984;29(3):143-54. doi:10.1179/sic.1984.29.3.143.

25. Aliatis I, Bersani D, Campani E, Casoli A, Lottici PP, Mantovan S, et al. Green pigments of the Pompeian artists' palette. Spectrochim Acta, Part A. 2009;3(3):532-8. doi:10.1016/j.saa.2008.11.009.

26. Rosi F, Miliani C, Borgia I, Brunetti BG, Sgamellotti A. Identification of nineteenth century blue and green pigments by in situ $x$-ray fluorescence and micro-Raman spectroscopy. J Raman Spectr. 2004;35(8-9):610-5. doi:10.1002/jrs.1180.

27. Bell IM, Clark RJH, Gibbs PJ. Raman Spectroscopic Library. http://www. chem.ucl.ac.uk/resources/raman/index.html Accessed November 20, 2015

\section{Submit your manuscript to a SpringerOpen ${ }^{\odot}$ journal and benefit from:}

- Convenient online submission

- Rigorous peer review

- Immediate publication on acceptance

- Open access: articles freely available online

- High visibility within the field

- Retaining the copyright to your article

Submit your next manuscript at $>$ springeropen.com 